\title{
Ship-induced solitary Riemann waves of depression in Venice Lagoon
}

\author{
Kevin E. Parnell ${ }^{\mathrm{a}, \mathrm{b}}$, Tarmo Soomere ${ }^{\mathrm{b}, \mathrm{c}, *}$, Luca Zaggia ${ }^{\mathrm{d}}$, Artem Rodin ${ }^{\mathrm{b}}$, \\ Giuliano Lorenzetti ${ }^{\mathrm{d}}$, John Rapaglia ${ }^{\mathrm{e}}$, Gian Marco Scarpa ${ }^{\mathrm{f}}$ \\ a College of Marine and Environmental Sciences and Centre for Tropical Environmental and Sustainability Sciences, James Cook University, \\ Queensland 4811, Australia \\ ${ }^{\mathrm{b}}$ Institute of Cybernetics at Tallinn University of Technology, Akadeemia tee 21, 12618 Tallinn, Estonia \\ c Estonian Academy of Sciences, Kohtu 6, 10130 Tallinn, Estonia \\ d Institute of Marine Sciences, National Research Council, Castello 2737/F, 30122 Venice, Italy \\ e Sacred Heart University Department of Biology, 5151 Park Avenue, Fairfield, CT 06825, USA \\ ${ }^{\mathrm{f}}$ Università Ca' Foscari, Dorsoduro 3246, 30123 Venice, Italy
}

\section{A R T I C L E I N F O}

\section{Article history:}

Received 17 September 2014

Received in revised form 30 October 2014

Accepted 3 December 2014

Available online 8 December 2014

Communicated by F. Porcelli

\section{Keywords:}

Ship wakes

Bernoulli wake

Nonlinear waves

Shallow-water waves

Riemann wave

Bore formation

\begin{abstract}
A B S T R A C T
We demonstrate that ships of moderate size, sailing at low depth Froude numbers (0.37-0.5) in a navigation channel surrounded by shallow banks, produce depressions with depths up to $2.5 \mathrm{~m}$. These depressions (Bernoulli wakes) propagate as long-living strongly nonlinear solitary Riemann waves of depression substantial distances into Venice Lagoon. They gradually become strongly asymmetric with the rear of the depression becoming extremely steep, similar to a bore. As they are dynamically similar, air pressure fluctuations moving over variable-depth coastal areas could generate meteorological tsunamis with a leading depression wave followed by a devastating bore-like feature.
\end{abstract}

(C) 2014 Elsevier B.V. All rights reserved.

\section{Introduction}

The wakes of ships range from the classical Kelvin wave groups $[1,2]$ at low Froude numbers, to intricate nonlinear mechanisms at transcritical speeds [3], and to Mach-type systems at supercritical speeds $[4,5]$. It is commonly believed that the largest environmental impacts come from long and long-crested almost nondispersive wave groups of significant amplitude [6,7]. Another recognized hazard is caused by solitonic waves that may result in high water velocities [8], elevate water levels at the shore [9] or build rogue waves [10]. The motion of a ship at finite depths also produces a depression region frequently called Bernoulli wake $[11,12]$. It is at times present at fairly low Froude numbers (down to 0.13 [13]) but is much more pronounced at moderate and high depth Froude numbers. It becomes often evident as a region of depression of nearly uniform depth [14-16], causes the draw-down effect (squat [17-22]) usually restricted to the navigation channel and may form structures similar to undular bore [23-25].

\footnotetext{
* Corresponding author.

E-mail address: soomere@cs.ioc.ee (T. Soomere).
}

If the channel has adjacent harbor areas or wide banks, the depressions may cause extensive dropdown in the harbor water level [26], spread far away from the channel [27], or play the largest role in sediment resuspension [27-29]. They may penetrate to a distance of many hundreds of meters from the navigation channel $[27,30]$. The resulting events have a characteristic dominant, leading trough, followed by small crests [28].

The core new feature of our analysis is the description of striking features of ship wakes in a fairly realistic situation where a navigation channel is surrounded by wide but very shallow banks. The existing studies [15] suggest that in such situations the usual definition of the (depth-based) Froude number may lead to inconsistent results and unexpectedly high waves of elevation may occur at relatively modest Froude numbers.

The purpose of this paper is to provide evidence about unprecedentedly deep depression waves in this geometry and get some insight into how the resulting depression wave can be replicated, how far it can propagate and which are (fairly unexpected) implications from the described phenomenon for adjacent fields of wave science. The resulting long-living waves of depression obviously cannot be treated as linear or weakly nonlinear. We make an attempt to describe such events using fully nonlinear theory of shallow-water waves in terms of simple or Riemann waves $[31,32]$. 


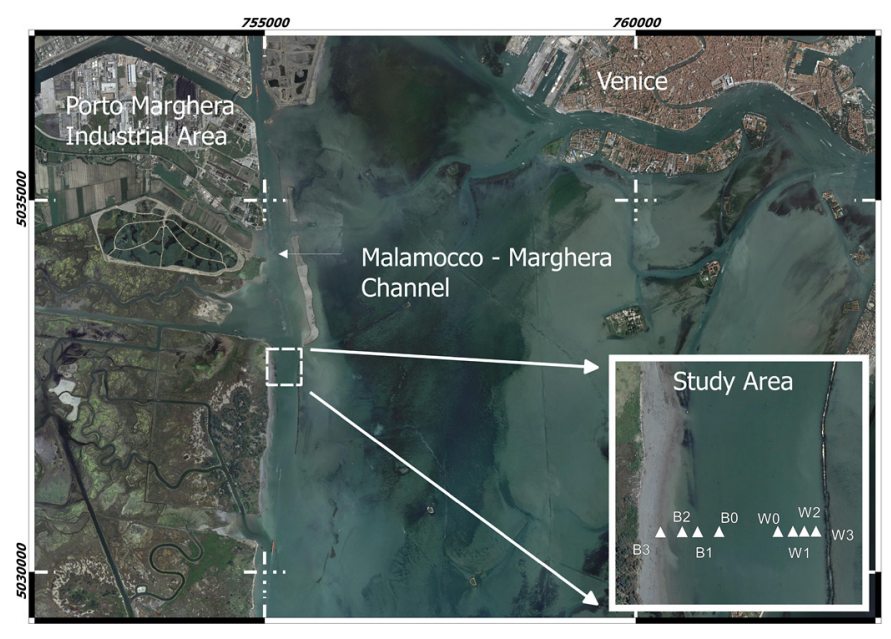

Fig. 1. The study area in the Malamocco-Marghera industrial channel. White triangles in the inset indicate the locations of pressure sensors in Fig. 2.

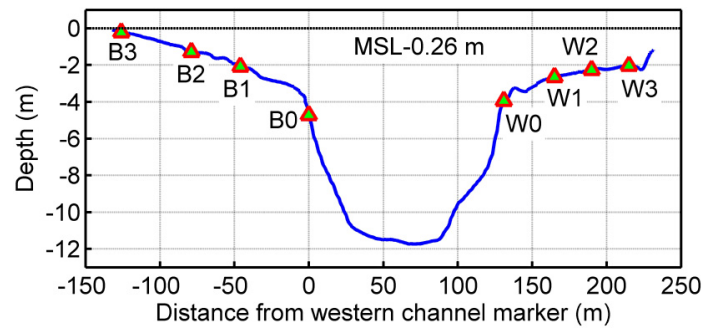

Fig. 2. Cross-section of the channel at the measurement site showing the location of pressure sensors (B0-B3, W0-W3). Distance is referenced to the western channel marker, and the depth is referenced to the local tidal datum $(0.26 \mathrm{~m}$ below mean sea level (MSL)).

\section{Ship-driven depressions}

Venice Lagoon, the largest Italian lagoon $\left(>500 \mathrm{~km}^{2}\right)$, is extremely shallow (with an average depth of $0.8 \mathrm{~m}$, the tidal range between 0.3 and $1.1 \mathrm{~m}$ ) and crossed by numerous tidal channels and artificial waterways, as deep as $10 \mathrm{~m}$ or more. It underwent severe erosion after the construction of the Malamocco-Marghera industrial channel [33]. The channel (Fig. 1) is orientated almost north-south, 11-12 m deep and $60 \mathrm{~m}$ wide bottom with relatively steep slopes $(\sim 10 \%)$ that rise from this depth to about $4 \mathrm{~m}$ deep water (Fig. 2). On the western side of the channel, the water shoals at a constant slope $(\sim 3 \%)$ to a shoreline. The eastern side of the channel has a smaller slope of $\sim 2 \%$ and is bordered by a permeable rock wall, the base of which is $90 \mathrm{~m}$ from the edge of the channel, at water depth $\sim 2 \mathrm{~m}$.

The measurements were performed using self-recording pressure sensors incorporated in various instruments (four InterOcean S4 current meters, one RBR Virtuoso wave gauge, one Ocean Seven CTD, two Esterline pressure sensors) at eight locations (Fig. 2). The InterOcean S4 instruments were fully time-synchronized while there may be some small error ( $\pm 10 \mathrm{~s})$ for other instruments. Sensors at the edges of the channel were suspended from the channel markers, and all other sensors were mounted on the seabed. Data were collected at either $2 \mathrm{~Hz}$ or $5 \mathrm{~Hz}$ over four sampling periods of 2 to 6 days in March-April 2014. The data for three ships (Table 1) are selected out of about 90 recorded examples to illustrate the range of appearances of the wakes for ships with similar parameters.

Water level records (Fig. 3) are presented as actual water depths at the time of ship passage. The ships did not produce any substantial transient sign-variable wave groups or solitary waves of elevation evidently because of relatively low speeds (7.7-10.4 knots,
$\left.F r_{d} \sim 0.37-0.5\right)$. The dominant feature of the ship passage was a deep depression. The typical duration of an event from still water level preceding to still water level following was $\sim 400 \mathrm{~s}$, with the characteristic solitary trough (V-shaped wave of depression) lasting typically $\sim 80 \mathrm{~s}$. The characteristics of the depression produced by different vessels varied significantly. The maximum water level drop recorded $(2.52 \mathrm{~m}$ from still water level at the shoreline side of the channel) was for Abu Dhabi Star, an unremarkable ship in terms of both its size and speed (Table 1 ).

A characteristic feature of the deepest depressions was the disparity of their maximum depths at the opposite margins of the channel. The maximum depth of the above depression by $A b u$ Dhabi Star was only about $1.6 \mathrm{~m}$ on the lagoon side. Domenico Ioveli produced a depression of $1.6 \mathrm{~m}$ on the lagoon side of the channel, but only $0.6 \mathrm{~m}$ on the shoreline side. The significant differences observed between the sides of the channel may reflect the position of the ship in the channel. Another reason may be the impact of the shape of the hulls. These depressions are, however, much larger than those previously reported $[27,29,34]$.

The depressions were almost perfectly symmetric in time with respect to their deepest point at the margins of the navigational channel (locations BO and W0 in Fig. 3). None of the recorded depressions had an elongated almost horizontal trough that is suggested by weakly nonlinear simulations $[15,16]$. This suggests that the depressions had strongly nonlinear nature.

The timing of the disturbance at subsequent sites (Fig. 3) indicates that the wave front moved obliquely with respect to the channel margin. Therefore, the subsequent recordings reflect the different parts of the wave crest. As around the measurement site the channel is essentially straight, its banks are almost homogeneous and the ship was moving at practically constant speed and direction, it is acceptable to assume that the properties of each depression only depend on the distance from the border of the channel.

The depression becomes gradually asymmetric with the distance from the channel margin. Its amplitude was usually smaller on the shoals compared to the channel edges but did not change significantly from one device to another (except at site B3, located in very shallow water where an increase in height was observed). The predominant process was an increase in the front/rear asymmetry of the wave profile. Its front slope became gradually less steep while the rear slope rapidly became steeper with the water surface exceeding the undisturbed level for a short period at the end of the some of the depression events. The asymmetry (defined as the ratio of typical values of the rear and front slopes) is usually well below 1.5 at sites WO and B0 and increases to the level of $2-3$ at sites $\mathrm{B} 1$ and $\mathrm{B} 2$, and to $\sim 10$ at sites $\mathrm{W} 3$ and B3. The overall appearance of the depression at sites B1-B3 and W1-W3 is a strongly skewed V-like shape. In most occasions an extremely steep section of the rear slope develops at the eastern (lagoon) side of the channel. Interestingly, virtually all records on the shoals demonstrate the development of a step, or a sequence of smaller steps on the rear slope of the depression wave.

\section{Riemann waves}

Based on the above arguments, we employ fully nonlinear 1D shallow-water equations for the description of the depression waves [31]:

$\frac{\partial u}{\partial t}+u \frac{\partial u}{\partial x}+g \frac{\partial \eta}{\partial x}=0, \quad \frac{\partial \eta}{\partial t}+\frac{\partial}{\partial x}[(h+\eta) u]=0$.

Here $h$ is the unperturbed water depth, $\eta$ is the water surface displacement, $u(x, t)$ is the depth-averaged horizontal velocity, $g$ is 
Table 1

Parameters of ships. The symbol $C^{*}$ stands for the blocking coefficient (width $\times$ draught/profile cross section area) and $F r_{d}$ is the depth-based Froude number.

\begin{tabular}{|c|c|c|c|c|c|c|c|c|c|}
\hline Date & Time & Ship & $\begin{array}{l}\text { Length, } \\
\text { m }\end{array}$ & $\begin{array}{l}\text { Width, } \\
\text { m }\end{array}$ & $\begin{array}{l}\text { Draught, } \\
\text { m }\end{array}$ & $\begin{array}{l}\text { Speed, } \\
\text { knots }\end{array}$ & Direction of travel & $C^{*}$ & $F r_{d}$ \\
\hline 28.03 & $8: 30$ & Pessada & 225 & 32 & 7 & 8.6 & South & 0.11 & 0.4 \\
\hline 01.04 & $15: 38$ & Abu Dhabi Star & 183 & 32 & 7.8 & 7.7 & North & 0.14 & 0.37 \\
\hline 22.04 & $6: 50$ & Domenico Ievoli & 146 & 20 & 6.6 & 10.4 & South & 0.07 & 0.5 \\
\hline
\end{tabular}
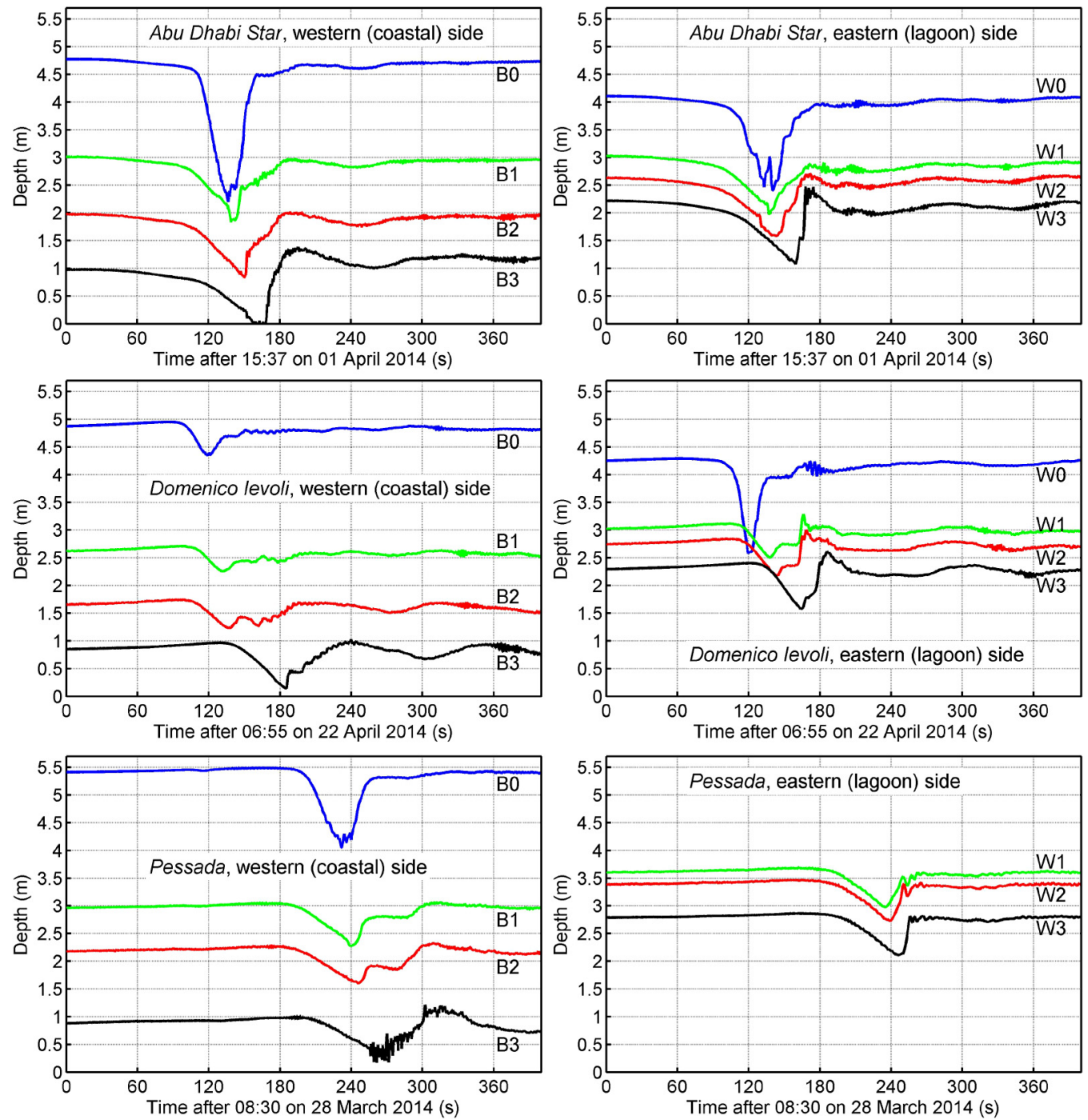

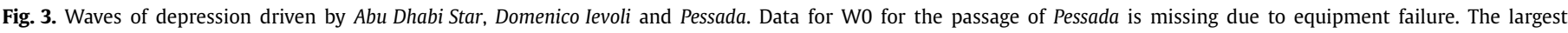
depressions caused drying of the coastal slope at location B3.

acceleration due to gravity, $x$ is the horizontal coordinate and $t$ is time. Eqs. (1), formally, are exact equations for the waves of arbitrary amplitude if dispersion and dissipation can be neglected. They can be written in the flux form as follows:

$\frac{\partial H}{\partial t}+\frac{\partial}{\partial x}(H u)=0, \quad \frac{\partial(H u)}{\partial t}+\frac{\partial}{\partial x}\left(H u^{2}+\frac{g H^{2}}{2}\right)=0$,

where $H=h+\eta$ is the instantaneous total water depth. A classical solution to Eqs. (1), (2) is a so-called simple or Riemann wave that is well known in nonlinear acoustics [35,36]. It can be described via the shape of the water surface $H(x, t)$ and the associated flow speed:

$H(x, t)=H_{0}[x-V t], \quad u(x, t)=2[\sqrt{g H(x, t)}-\sqrt{g h}]$, where $H_{0}(x)$ describes the initial water surface profile. The local speed of nonlinear wave propagation is $V(x, t)=3 \sqrt{g H(x, t)}-$ $2 \sqrt{g h}$. The Riemann waves of depression always propagate slower than the linear shallow-water wave speed $\sqrt{g h}$ and tend to form a skewed shape with characteristic steep rear slope [31,32,37]. A Riemann wave of depression can only propagate over reasonable distances if its trough is not too deep: for $\left|\eta_{\max }\right|>(5 / 9) h$, the wave would almost instantly break [32,37]. This condition was only met at measurement site B3 located in less than $1 \mathrm{~m}$ deep water. Differently from several families of weakly nonlinear equations, solution (3) may be a long-living wave of depression. This solution has been often used to analyze the properties of waves produced, for example, by a wavemaker $[32,37,38]$. Here, ships play the role of a wavemaker. 

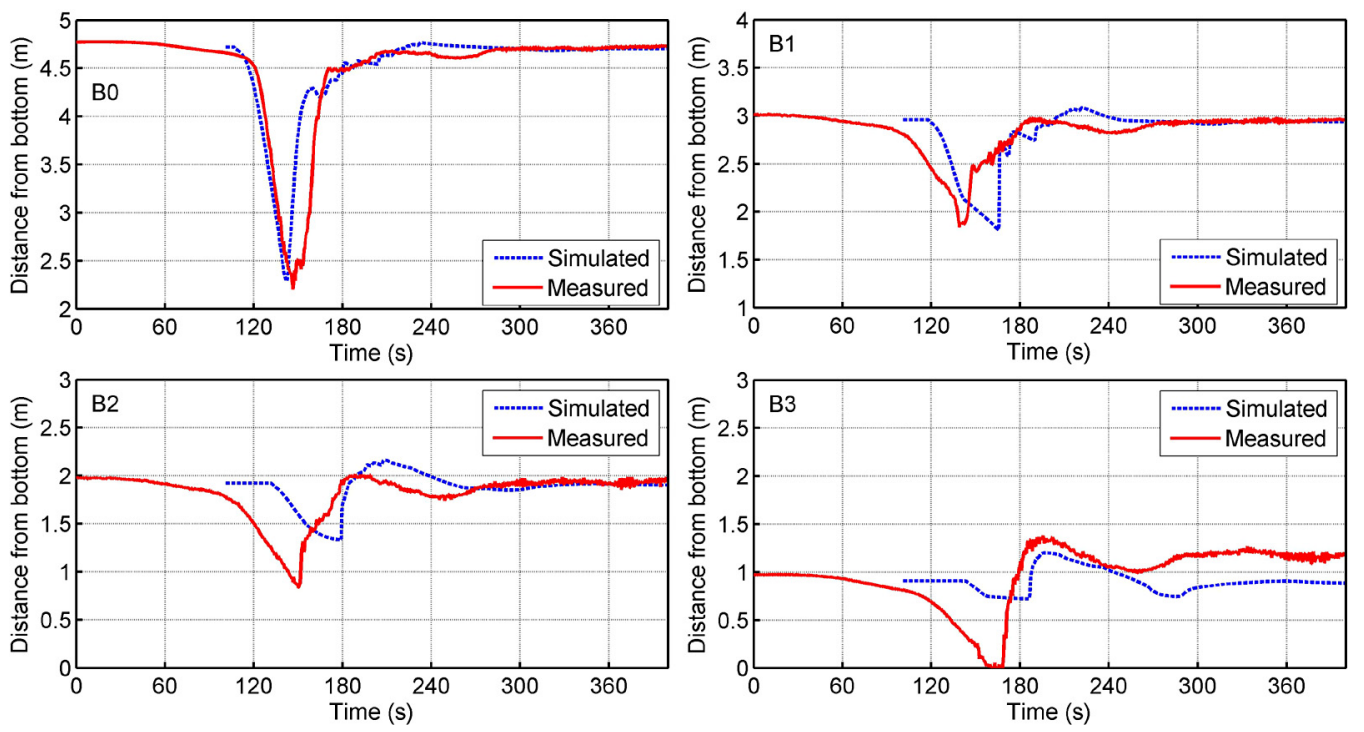

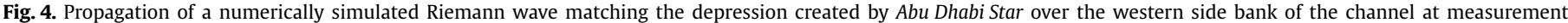
sites B0-B3.

\section{Propagation of simulated Riemann waves}

The propagation of depressions was simulated using the CLAWPACK package, which solves Eqs. (2) with the finite volume method [39]. The numerical solution follows the mass conservation law with an accuracy of about $10^{-6} \%$ [38]. The boundary conditions were formulated as the Sommerfeld radiation condition. To smooth out small-scale ripples and other immaterial features of the measured profiles, at each side of the channel (near W0 or B0 in Fig. 4) the initial wave was assumed to have a Gaussian pulse of negative polarity. The amplitude, location and width of this pulse were chosen to match the maximum depth of the depression, its timing and the slope of the wave front at site W0 or BO. Another series of simulations (not shown) used an inverted shape of a Kortewegde Vries soliton, defined in a similar manner, and led to almost coinciding results. This suggests that the basic properties of the propagation of the depression are largely defined by the slope and width of the disturbance. The flow velocity for this smoothed depression was defined using Eq. (3). The spatial grid step was $20 \mathrm{~cm}$. Its refinement by 2-3 times leads to the difference in wave amplitudes of no more than $0.5 \%$. The time step $(0.5 \mathrm{~s})$ has been chosen to satisfy the Courant-Friedrichs-Levy condition.

In spite of this rough approximation of the initial wave profile, the simulations replicate the major features of nonlinear propagation of depressions such as gradual smoothening of the wave front and development of steeper rear slope (Fig. 4). A certain time shift between the measured and simulated waves evidently reflects oblique propagation of the depressions with respect to the cluster of devices while the simulated wave front was assumed to propagate perpendicularly to the channel margin. The amplitude of the wave and the development of rear-front asymmetry (as defined above) are appreciably replicated at sites W1 and W2. The asymmetry of the simulated depression at W1-W3 and B1-B3 at times (when a step is developed in the rear slope) exceeds the asymmetry of the measured profile by an order of magnitude. The emergence of such steps in both recorded and simulated data is characteristic to the formation of the steep rear slope of large-amplitude Riemann waves of depression from Gaussian initial disturbances [38]. These steps are apparently fingerprints of reflected waves that propagate in the opposite direction to the depression wave if $\left|\eta_{\max }\right|$ approaches (5/9)h. Their replication is not perfect but clear qualitative match is evident at all sites. A mismatch between the measured and simulated amplitudes at site B3

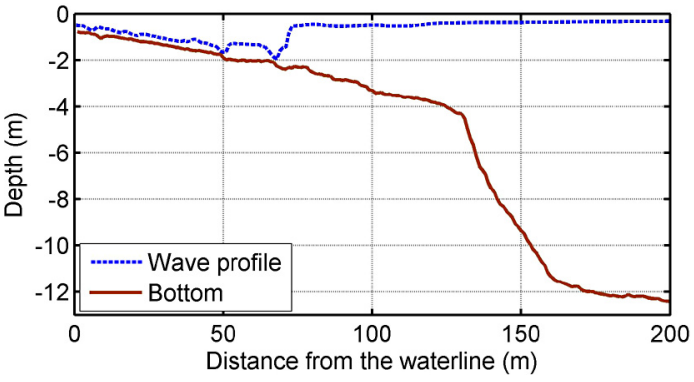

Fig. 5. The simulated wave profile produced by the depression wave of Pessada (Fig. 3) on the western side of the channel $80 \mathrm{~s}$ after reaching the channel margin. To the left of the trough there is sheet flow down the profile. Some fluctuations ahead of the shock are evidently caused by bottom profile irregularities.

is evidently related to the problems of replication of the drying effect.

Similarly to the measured data in Fig. 3, the propagation of the largest simulated depressions along the western (coastal) side of the channel led to almost drying out of the seabed (Fig. 5). For the largest waves along this shoreline the condition $\left|\eta_{\max }\right|>(5 / 9) h$ is usually met starting from a certain location along the profile. A shock-like rear slope of the trough appears almost instantaneously at this location and the wave propagates into the shallow area as a bore. In general these troughs can be well described by the numerical solution which in extreme cases can have different nonlinear effects [40].

\section{Concluding remarks}

Unexpectedly high (up to $2.5 \mathrm{~m}$ ) solitary depression waves are generated by moderately-sized ships sailing at very moderate depth Froude numbers $(<0.5)$ and blocking coefficients $(<0.14)$ in channels surrounded by shallow banks. These depressions can propagate to a considerable distance (up to $500 \mathrm{~m} \mathrm{[27])} \mathrm{away} \mathrm{from}$ the navigation channel.

These disturbances are symmetric in time within the channel. The problem is specific to the case when the depression penetrates to a wide and shallow shoal (estuary, river bank, shallow lagoon, etc.). When moving as extremely long (typical periods of $40-50 \mathrm{~s}$ and lengths of $250-300 \mathrm{~m}$ ) waves in very shallow water (2-3 m), they can be described in terms of strongly nonlinear sim- 
ple or Riemann waves. Nonlinearity acts here in an expected way, by building up a steep rear slope or even bore-like features to the disturbance. This happens within less than ten seconds and over a distance of a few tens of meters.

A secondary impact of nonlinearity becomes evident as a temporary step-like profile of the rear slope. It is debatable which mechanism causes the small features seen in the observations at this site. For example, incipient undular bore formation probably modifies this part of the wake of Pessada at W1-W3 (Fig. 3) whereas a sort of reflection from the bottom may play a role in the evolution of Domenico Ieovoli wake at sites B3 and W1-W3 (Fig. 3). More importantly, the resulting water velocities, sediment resuspension and the overall environmental impact will be much (at least several times) larger than those evaluated based on the linear or weakly nonlinear approaches.

The presented material has important implications for reevaluation of the chances of generation of a large tsunami wave of depression, or a similar wave preceded by a depression. The common understanding is that a meteorological tsunami is generated as a wave of elevation when an atmospheric disturbance moves at a near-critical speed. This wave may later develop, e.g., an $N$-wave preceded by a depression [41]. The dynamical similarity of ship wakes and meteorological tsunamis (a well-known feature explained in more detail in [42]) suggests that a substantial meteorological tsunami of depression can be directly generated by an atmospheric disturbance moving with a speed much less than the critical one along an abrubt scarp in the seabed, and that this process is possible for an often occurring geometry of seabed. Such tsunamis with a leading depression wave are eventually followed by a devastating bore-like feature.

\section{Acknowledgements}

The field studies were undertaken while K. Parnell was hosted by CNR-ISMAR, Venice, Italy, and were funded by the project Ritmare (SP3-WP3-A1). The underlying research into Riemann waves was funded by the Estonian Science Foundation (grant No. 9125), targeted financing by the Estonian Ministry of Education and Research (grant SF0140007s11), and through support of the European Regional Development Fund to the Centre of Excellence in Non-linear Studies CENS and project TERIKVANT (grant 3.2.0802.11-0043). A. Rodin is grateful for the support of the DoRa program to his PhD studies.

\section{Appendix A. Supplementary material}

Supplementary material related to this article can be found online at http://dx.doi.org/10.1016/j.physleta.2014.12.004.

\section{References}

[1] J. Lighthill, Waves in Fluids, Cambridge University Press, 1978

[2] J.N. Newman, Marine Hydrodynamics, MIT Press, 1977.

[3] T. Soomere, Nonlinear components of ship wake waves, Appl. Mech. Rev. 60 (2007) 120-138.

[4] M. Rabaud, F. Moisy, Ship wakes: Kelvin or Mach angle?, Phys. Rev. Lett. 110 (2013) 214503.

[5] A. Darmon, M. Benzaquen, E. Raphael, Kelvin wake pattern at large Froude numbers, J. Fluid Mech. 738 (2014) R3.

[6] K.E. Parnell, H. Kofoed-Hansen, Wakes from large high-speed ferries in confined coastal waters: management approaches with examples from New Zealand and Denmark, Coast. Manage. 29 (2001) 217-237.

[7] T. Soomere, Fast ferry traffic as a qualitatively new forcing factor of environmental processes in non-tidal sea areas: a case study in Tallinn Bay, Baltic Sea, Environ. Fluid Mech. 5 (2005) 293-323.
[8] D. Neuman, E. Tapio, D. Haggard, K. Laws, R. Bland, Observation of long waves generated by ferries, Can. J. Remote Sens. 27 (2001) 361-370.

[9] T. Soomere, K.E. Parnell, I. Didenkulova, Water transport in wake waves from high-speed vessels, J. Mar. Syst. 88 (2011) 74-81.

[10] P. Peterson, T. Soomere, J. Engelbrecht, E. van Groesen, Soliton interaction as a possible model for extreme waves in shallow water, Nonlinear Process. Geophys. 10 (2003) 503-510.

[11] W. Graff, Untersuchungen über die Ausbildung des Wellenwiderstandes im Bereich der Stauwellengeschwindigkeit in flachem, seitlich beschränktem Fahrwasser, Schiffstechnik 9 (1962) 110-122 (in German).

[12] T. Jiang, Ship Waves in Shallow Water, Fortschritt-Berichte VDI, Reihe 12, Nr. 466, VDI Verlag, Düsseldorf, Germany, 2001.

[13] C.E. Janson, Bernoulli waves in deep and shallow water at low speed, Ship Technol. Res. 49 (2002) 142-147.

[14] P.G. Baines, Topographic Effects in Stratified Flows, Cambridge University Press, 1997.

[15] T. Torsvik, G. Pedersen, K. Dysthe, J. Waterw. Port Coast. Ocean Eng. 135 (2007) 120.

[16] T. Torsvik, I. Didenkulova, T. Soomere, K.E. Parnell, Variability in spatial patterns of long nonlinear waves from fast ferries in Tallinn Bay, Nonlinear Process. Geophys. 16 (2009) 351-363.

[17] T. Constantine, On the movement of ships in restricted waterways, J. Fluid Mech. 9 (1961) 247-256.

[18] P.M. Naghdi, M.B. Rubin, On the squat of a ship, J. Ship Res. 28 (1984) 107-117.

[19] A. Millward, A review of the prediction of squat in shallow water, J. Navig. 49 (1996) 77-88.

[20] T.P. Gourlay, Ship squat in water of varying depth, Int. J. Marit. Eng. 145 (2003) $1-8$.

[21] T.P. Gourlay, E.O. Tuck, The maximum sinkage of a ship, J. Ship Res. 45 (2001) $50-58$.

[22] T.P. Gourlay, A simple method for predicting the maximum squat of a highspeed displacement ship, Mar. Technol. 43 (2006) 146-151.

[23] T. Akylas, On the excitation of long nonlinear water waves by a moving pressure distribution, J. Fluid Mech. 141 (1984) 455-466

[24] R.H.J. Grimshaw, N. Smyth, Resonant flow of a stratified flow over topography, J. Fluid Mech. 169 (1986) 429-464.

[25] S.J. Lee, G.T. Yates, T.Y. Wu, Experiments and analyses of upstream-advancing solitary waves generated by moving disturbances, J. Fluid Mech. 199 (1989) 569-593.

[26] B. Forsman, From bow to beach, in: SSPA Highlights, vol. 3, 2001, pp. 4-5.

[27] J. Rapaglia, L. Zaggia, K. Ricklefs, M. Gelinas, H. Bokuniewicz, Characteristics of ships' depression waves and associated sediment resuspension in Venice Lagoon, Italy, J. Mar. Syst. 85 (2011) 45-56.

[28] M. Gelinas, H. Bokuniewicz, J. Rapaglia, K.M.M. Lwiza, Sediment resuspension by ship wakes in the Venice Lagoon, J. Coast. Res. 29 (2013) 8-17.

[29] G. Göransson, M. Larson, J. Althage, Ship-generated waves and induced turbidity in the Göta alv River in Sweden, J. Waterw. Port Coast. Ocean Eng. 140 (2014) 04014004, http://dx.doi.org/10.1061/(ASCE)WW.1943-5460.0000224.

[30] T.M. Ravens, R.C. Thomas, Ship wave-induced sedimentation of a tidal creek in Galveston bay, J. Waterw. Port Coast. Ocean Eng. 134 (2008) 21-29.

[31] G.B. Whitham, Linear and Nonlinear Waves, Wiley, New York, 1974.

[32] I.I. Didenkulova, N. Zahibo, A.A. Kurkin, E.N. Pelinovsky, Steepness and spectrum of a nonlinearly deformed wave on shallow waters, Izvestiya Atmos. Ocean. Phys. 42 (2006) 773-776.

[33] A. Sarretta, S. Pillon, E. Molinaroli, S. Guerzoni, G. Fontolan, Sediment budget in the Lagoon of Venice, Italy, Cont. Shelf Res. 30 (2010) 934-949.

[34] H. Balzerek, J. Kozlowski, Ship-induced riverbank and harbour damage. Evidence for claims processing, Hydro International (September 2007) 2-7.

[35] O. Rudenko, S. Soluyan, Theoretical Background of Nonlinear Acoustics, Plenum, New York, 1977.

[36] J.K. Engelbrecht, V.E. Fridman, E.N. Pelinovski, Nonlinear Evolution Equations, Pitman Research Notes in Mathematics Series, vol. 180, Longman, London, 1988

[37] N. Zahibo, I. Didenkulova, A. Kurkin, E. Pelinovsky, Steepness and spectrum of nonlinear deformed shallow water wave, Ocean Eng. 35 (2008) 47-52.

[38] I. Didenkulova, E. Pelinovsky, A. Rodin, Nonlinear interaction of large-amplitude unidirectional waves in shallow water, Estonian J. Eng. 17 (2011) 289-300.

[39] R.J. LeVeque, Finite-Volume Methods for Hyperbolic Problems, Cambridge University Press, 2004.

[40] E.N. Pelinovsky, A.A. Rodin, Transformation of a strongly nonlinear wave in a shallow-water basin, Izvestiya Atmos. Ocean. Phys. 48 (2012) 343-349.

[41] S. Tadepalli, C.E. Synolakis, Model for the leading waves of tsunamis, Phys. Rev. Lett. 77 (1996) 2141-2144.

[42] I. Didenkulova, E. Pelinovsky, T. Soomere, Can the waves generated by fast ferries be a physical model of tsunami?, Pure Appl. Geophys. 168 (2011) 2071-2082 